\title{
Identification of the Most Fragile Component for a Typical RC Bridge Using Seismic Fragility Curves
}

\author{
Yang LIU, Da-Gang LU, Ming-Gang HUANG
}

\begin{abstract}
This paper identifies the most fragile component of a typical reinforced concrete $(\mathrm{RC})$ continuous girder bridge through the seismic fragility analysis. The typical bridge, Liang-Zi River bridge located in Shandong Province of China, is taken as the case study. The Cloud analysis approach is adopted to construct the probabilistic seismic demand models (PSDMs). Both of the record-to-record uncertainty in ground motions and the structural model uncertainty are considered in the PSDMs by using several approaches such as the selection of real ground motion records from the NGA-West2 database and the Latin Hypercube Sampling (LHS) approach. The damage limit states defined refer to piers and bearings which are commonly regarded as the fragile components. Furthermore, the seismic fragility curves of components and the bridge system are developed. Results show that the middle piers are more fragile than the side piers; the bearings are more fragile than piers; it is different from experiences that the fixed bearings at the top of the middle pier are not always more fragile than sliding bearings at both of the transverse and longitudinal loading conditions.
\end{abstract}

Keywords: fragile component; numerical simulation; RC continuous girder bridge; seismic fragility; uncertainty

\section{INTRODUCTION}

The reinforced concrete (RC) continuous girder bridge is spread all over the world for its advantages of the convenience of the design and construction. In China, tens of thousands of this type of bridges and overpasses are designed and built in transportation lifeline systems. The failure or even severe damage of the bridges will lead to traffic disruptions and rescue delay after seismic disasters shocking. A series of strong earthquake disasters occurred in China, such as the Chi-Chi Earthquake in 1999 and Wen-Chuan Earthquake in 2008, and revealed the important role played by the traffic lifeline in disaster relief [1]. The seismic fragility is an essential model to predict the seismic performance of a structure under earthquakes. Seismic fragility is commonly defined as the exceedance probability of seismic demand over each damage limit state at the given intensity level [2]. Generally, the fragility curves are used to assess the fragility of components or systems. Seismic fragility of the lifeline system should be fully assessed, especially for the seismic fragility of traditional bridge types with widespread applications.

The next-generation performance-based earthquake engineering (PBEE) framework proposed by PEER is an efficient and useful probabilistic approach to assess the performance of engineering structures [3]. In the framework, three major steps are carried out to generate seismic fragility curves, including the selection of a representative suite of ground motion records, the probabilistic seismic demand analysis (PSDA) and the probabilistic seismic capacity analysis (PSCA) [4].

The ground motion records can be selected according to the parameters which are used to represent the characteristics of structures and the site. Commonly, the natural vibration period is used as the parameter for the structure, while the distance from the site to the source and the earthquake magnitude are the fundamental seismic parameters for the site. This is because these parameters have clear conceptual meaning and are easy to be calculated. After the selection of appropriate intensity measures, the record-to-record uncertainty is considered herein through a selection of multiple ground motion records [5].

The goal of the PSDA is to construct the relationship of the seismic intensity level (represented by the value of the selected intensity measures) and the structural dynamic response (typically known as seismic demand) [6]. At each level of seismic intensity, the responses of a structure can be calculated by Time-History Analysis (THA) approach. Based on the basic method of THA, several improved approaches such as Incremental Dynamic Analysis (IDA), Multiple Stripe Analysis (MSA), and Cloud Analysis have been proposed. Compared to the others, the Cloud method is more extensively used for its simplification and the relatively small number required of THA [7].

Both of the uncertainties in structural damage and in the definition procedure of damage limit states can be considered in PSCA task, which can be carried out by numerical simulations or experiments.

In China, many researchers focus on the assessment of the seismic fragility of long-span and large-scale bridges whose dynamic response is complex and their seismic performance is difficult to be predicted. However, the RC continuous girder bridges in China are still not adequately investigated. It is argued that the most fragile component of this traditional bridge type is the fixed bearing at the middle pier. Therefore, the main target of this study is the fragile component identification for this type of bridge.

In this paper, the typical $\mathrm{RC}$ continuous girder bridge included in Qingzhou-Linshu highway system in China is taken as the case study. The peak ground acceleration $(P G A)$ and the spectral acceleration for the fundamental period denoted by $S_{\mathrm{a}}\left(T_{1}\right)$ or simply $S_{\mathrm{a}}$ are selected as seismic intensity measures (IMs). A suite of ground motion records is selected based on the NGA-West 2 Database [8]. The maximum displacement ductility of piers and the maximum displacements of bearings are defined as engineering demand parameters (EDPs). The IMs are input variables regarding the input intensity while the EDPs are output variables to represent the structural response. For the probability analysis, each ground motion record and each structural numerical model are paired as an earthquake-structure sample. Considering the uncertainty of the material parameters, the Latin Hypercube Sampling (LHS) approach [9] is used to generate a total of 100 samples. After that, the Cloud Analysis Approach is used to estimate the structural response. The probabilistic seismic demand models (PSDMs) are used to derive the relationship between IMs and EDPs. Based on these demand models and indices for seismic damage limit 
states, seismic fragility curves of components and the bridge system are then developed.

The goal of this paper is twofold as follows: to identify the most fragile component of RC continuous girder bridge using fragility curves; to discuss the seismic system fragility of this typical bridge.

\section{TYPICAL RC CONTINUOUS GIRDER BRIDGE \\ 2.1 Description of the Bridge}

The Liang-Zi river bridge in Qingzhou-Linshu highway line in Shandong Province is a typical 4-spans RC continuous girder bridge which is designed according to the China bridge design code JTG D62-2004 [10] and seismic design code JTG/T B02-01-2008[11]. The prototype bridge is $72.0 \mathrm{~m}$ long and consists of four spans of $18.0 \mathrm{~m}$. The total width of the road cross-section is 8.9 $\mathrm{m}$, with carriageway $7.5 \mathrm{~m}$ wide without sidewalks. This is a typical overpass cross-section with 2 traffic lanes. The cross-section of the main beam is single-box single-room section with the total height of $1.5 \mathrm{~m}$ (Fig. 1). The thickness of the top concrete slab is equal to $25 \mathrm{~cm}$. The box beam is simply supported on normal damping (damping ratio $\leq$ $12 \%$ ) rubber bearings at the intermediate pier. At the abutments, the sliding bearings are used. The column type pier is $7.0 \mathrm{~m}$ of height with the diameter of $1.5 \mathrm{~m}$, while 25 of reinforcement bars with a diameter of $32 \mathrm{~mm}$ are arranged along the longitudinal direction.

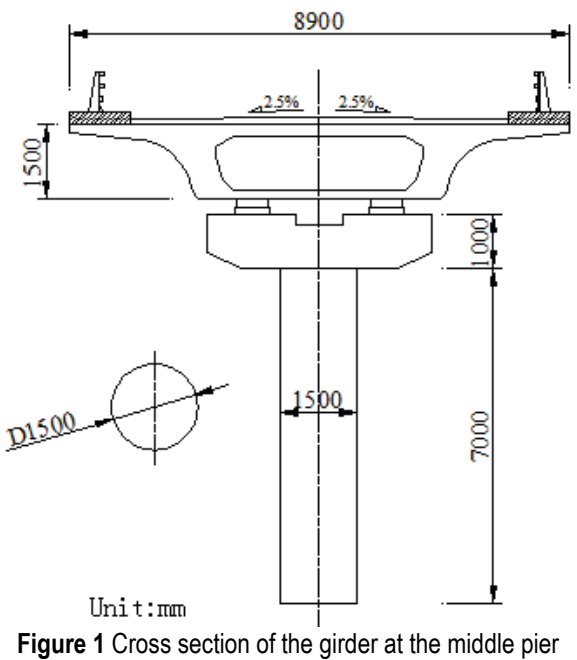

The grade of concrete for superstructure is $\mathrm{C} 40$ with the thickness of concrete cover $5 \mathrm{~cm}$, while the $\mathrm{C} 30$ grade concrete is used for piers and abutments [10]. The reinforcement bars are made of grade HRB335 steel [10]. It is assumed that the foundation soil is categorized as type $\mathrm{C}$ and the soil-structure interaction (SSI) effect is neglected in this case.

\subsection{Finite Element Model of the Bridge}

In this study, the 3D finite element (FE) model is built on the Open Sees platform and shown in Fig. 2 [12]. In this FE model, the nonlinearities of material are considered. The concrete 01 type is selected as the mechanical model of concrete according to Kent-Scott-Park model where the tensile strength of concrete is neglected [12], with the concrete Poisson's ratio of 0.2 , Young's modulus $E=$
$30000 \mathrm{MPa}$ and $32500 \mathrm{MPa}$. Meanwhile, the steel 01 type, an elastic-perfectly plastic model, has been selected as the mechanical model of steel bars assumed that the tensile properties are the same as the properties of compression. The Young's modulus of steel is $200000 \mathrm{MPa}$. The aforementioned values of parameters are obtained from the Chinabridge design code [10].

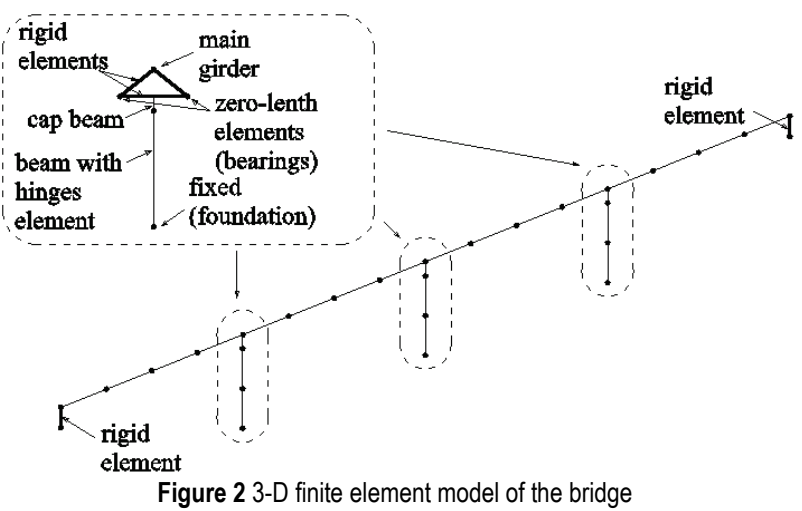

The typical RC box beam is modeled using beamcolumn elements. Since the superstructure is not expected to yield, the simplified modeling solution described above is preferred to drastically reduce the computational cost of the numerous time history analyses performed for this study. For the RC piers, the nonlinear beam elements with fiber sections are adopted. The piers are fixed on the ground with the assumption of neglecting the SSI effect. The abutments are simplified and the supports at the end of beams are simulated by sliding bearings.

The bearings are simulated by zero-length elements which are similar to springs with different stiffness. According to many test results of dynamic behaviour, the hysteretic curves of the plate rubber bearings are the narrow shape. So their mechanical behaviours can be simplified as linear-elastic behaviour. In this FE model, the longitude stiffness of the plate rubber bearings, denoted as $K_{\mathrm{H}}$, is calculated according to guidelines for the seismic design of highway bridges as follows [11]

$K_{\mathrm{H}}=\frac{A_{\mathrm{R}} \cdot G}{\sum t_{\mathrm{e}}}$

where $A_{\mathrm{R}}$ is the shear area of a bearing and is assumed as $24.75 \mathrm{~cm}^{2}, \Sigma t_{\mathrm{e}}$ the total thickness of all rubber layers with a thickness of $50 \mathrm{~mm}, G$ the shear modulus of each rubber layer with a value of $1200 \mathrm{kN} / \mathrm{m}^{3}$. The aforementioned values are obtained from the China bridge design code [10] The Polytetrafluoroethylene (PTFE) slide plate bearing is assumed as the elastic-perfectly plastic material. Before sliding, this type bearing is assumed as the normal plate rubber bearing. Therefore, its stiffness before sliding can be calculated by the approach as the same as that using for plate rubber bearings. The critical displacement of sliding, denoted as $x_{y}$, is defined as

$x_{y}=\frac{F_{\max }}{K}=\frac{f \cdot N}{K}$

in which, $F_{\max }$ is the critical friction force, $K$ is the initial stiffness which can be referred to $K_{\mathrm{H}}$, the coefficient of 
sliding friction $f=0.05, N$ is the dead load carried by each bearing and is about $2060 \mathrm{kN}$ in this case.

\subsection{Eigen-value Analysis Results}

Using the Rayleigh damping model, the Eigen-value Analysis has been carried out and the results are shown in
Tab. 1. The dynamic response of this bridge shows that the lower vibration modes are dominated.

Table 1 Results of the Eigen-value Analysis

\begin{tabular}{|c|c|c|}
\hline Order & Periods (s) & Vibration modes \\
\hline 1 & 1.16 & Single transverse bending \\
\hline 2 & 1.05 & Single longitudinal bending \\
\hline 3 & 0.88 & Double transverse bending \\
\hline 4 & 0.62 & Triple transverse bending \\
\hline
\end{tabular}

Table 2 Selection of ground motion records

\begin{tabular}{|c|c|c|c|c|c|c|c|}
\hline $\mathrm{SN}$ & Name and direction & $P G A(\mathrm{~g})$ & $S_{\mathrm{a}}(\mathrm{g})$ & $\mathrm{SN}$ & Name and direction & $P G A(\mathrm{~g})$ & $S_{a}(\mathrm{~g})$ \\
\hline 1 & CHICHI/CHY002-E & 0.117243 & 0.2468 & 51 & CHICHI/CHY082-N & 0.062621 & 0.0704 \\
\hline 2 & CHICHI/CHY002-N & 0.146884 & 0.2318 & 52 & CHICHI/CHY082-W & 0.067110 & 0.1118 \\
\hline 3 & CHICHI/CHY004-E & 0.099107 & 0.1154 & 53 & CHICHI/CHY088-E & 0.134140 & 0.1635 \\
\hline 4 & CHICHI/CHY004-N & 0.099904 & 0.1822 & 54 & CHICHI/CHY088-N & 0.258702 & 0.2841 \\
\hline 5 & CHICHI/CHY006-E & 0.364422 & 0.5256 & 55 & CHICHI/CHY092-E & 0.111286 & 0.2874 \\
\hline 6 & CHICHI/CHY006-N & 0.345195 & 0.7952 & 56 & CHICHI/CHY092-N & 0.082286 & 0.2088 \\
\hline 7 & CHICHI/CHY008-E & 0.130217 & 0.1882 & 57 & CHICHI/CHY101-N & 0.440103 & 0.7558 \\
\hline 8 & CHICHI/CHY008-N & 0.120011 & 0.2087 & 58 & CHICHI/CHY101-W & 0.352887 & 0.4541 \\
\hline 9 & $\mathrm{CHICHI} / \mathrm{CHY} 012-\mathrm{E}$ & 0.052537 & 0.1167 & 59 & CHICHI/CHY104-E & 0.161863 & 0.3377 \\
\hline 10 & CHICHI/CHY012-N & 0.062980 & 0.1164 & 60 & CHICHI/CHY104-N & 0.186683 & 0.2532 \\
\hline 11 & CHICHI/CHY014-N & 0.105241 & 0.1002 & 61 & CHICHI/CHY107-N & 0.061810 & 0.1262 \\
\hline 12 & CHICHI/CHY014-W & 0.069590 & 0.0909 & 62 & CHICHI/CHY107-W & 0.069018 & 0.2304 \\
\hline 13 & CHICHI/CHY015-N & 0.114892 & 0.3163 & 63 & CHICHI/HWA005-E & 0.147236 & 0.1832 \\
\hline 14 & CHICHI/CHY015-W & 0.120788 & 0.2221 & 64 & CHICHI/HWA005-N & 0.138548 & 0.4269 \\
\hline 15 & CHICHI/CHY016-E & 0.095857 & 0.1482 & 65 & CHICHI/HWA031-N & 0.101244 & 0.3173 \\
\hline 16 & CHICHI/CHY016-N & 0.105137 & 0.2866 & 66 & CHICHI/HWA032-N & 0.112408 & 0.0716 \\
\hline 17 & CHICHI/CHY017-N & 0.042432 & 0.0872 & 67 & CHICHI/HWA032-W & 0.147139 & 0.1297 \\
\hline 18 & CHICHI/CHY017-W & 0.033717 & 0.0687 & 68 & CHICHI/HWA034-N & 0.142479 & 0.0628 \\
\hline 19 & CHICHI/CHY024-N & 0.175403 & 0.2216 & 69 & CHICHI/TAP003-E & 0.125641 & 0.4023 \\
\hline 20 & CHICHI/CHY024-W & 0.278026 & 0.4159 & 70 & CHICHI/TAP003-N & 0.106431 & 0.3378 \\
\hline 21 & CHICHI/CHY025-N & 0.153172 & 0.2865 & 71 & CHICHI/TAP005-E & 0.136560 & 0.5292 \\
\hline 22 & CHICHI/CHY025-W & 0.159217 & 0.3938 & 72 & CHICHI/TAP005-N & 0.075139 & 0.2699 \\
\hline 23 & CHICHI/CHY026-N & 0.065531 & 0.1674 & 73 & CHICHI/TAP006-E & 0.104613 & 0.2746 \\
\hline 24 & CHICHI/CHY026-W & 0.076132 & 0.2456 & 74 & CHICHI/TAP006-N & 0.070820 & 0.3614 \\
\hline 25 & CHICHI/CHY027-N & 0.052732 & 0.1031 & 75 & CHICHI/TAP014-E & 0.113925 & 0.3235 \\
\hline 26 & CHICHI/CHY027-W & 0.057238 & 0.0899 & 76 & CHICHI/TAP014-N & 0.072761 & 0.2540 \\
\hline 27 & CHICHI/CHY032-N & 0.078081 & 0.1684 & 77 & CHICHI/TCU040-N & 0.122949 & 0.1965 \\
\hline 28 & CHICHI/CHY032-W & 0.088480 & 0.1624 & 78 & CHICHI/TCU040-W & 0.148600 & 0.2596 \\
\hline 29 & CHICHI/CHY033-E & 0.055712 & 0.0577 & 79 & CHICHI/TCU056-N & 0.134377 & 0.2241 \\
\hline 30 & CHICHI/CHY033-N & 0.108440 & 0.0964 & 80 & CHICHI/TCU056-W & 0.133742 & 0.2430 \\
\hline 31 & CHICHI/CHY034-N & 0.098194 & 0.1865 & 81 & CHICHI/TCU110-N & 0.179815 & 0.5874 \\
\hline 32 & CHICHI/CHY034-W & 0.099789 & 0.1523 & 82 & CHICHI/TCU110-W & 0.180392 & 0.4213 \\
\hline 33 & CHICHI/CHY035-N & 0.246186 & 0.4217 & 83 & CHICHI/TCU111-N & 0.099274 & 0.2508 \\
\hline 34 & CHICHI/CHY035-W & 0.251711 & 0.5984 & 84 & CHICHI/TCU111-W & 0.135536 & 0.3118 \\
\hline 35 & CHICHI/CHY036-N & 0.206601 & 0.3197 & 85 & CHICHI/TCU115-N & 0.116916 & 0.1674 \\
\hline 36 & CHICHI/CHY036-W & 0.293838 & 0.5562 & 86 & CHICHI/TCU115-W & 0.095638 & 0.1599 \\
\hline 37 & CHICHI/CHY039-E & 0.066644 & 0.0497 & 87 & CHICHI/TCU116-N & 0.147980 & 0.2858 \\
\hline 38 & CHICHI/CHY039-N & 0.058855 & 0.0544 & 88 & CHICHI/TCU116-W & 0.184204 & 0.5878 \\
\hline 39 & CHICHI/CHY044-N & 0.077235 & 0.2079 & 89 & CHICHI/TCU117-N & 0.120314 & 0.2794 \\
\hline 40 & CHICHI/CHY044-W & 0.055253 & 0.1259 & 90 & CHICHI/TCU117-W & 0.119099 & 0.3927 \\
\hline 41 & CHICHI/CHY046-E & 0.135980 & 0.1342 & 91 & CHICHI/TCU118-N & 0.092395 & 0.1321 \\
\hline 42 & CHICHI/CHY046-N & 0.118981 & 0.1319 & 92 & CHICHI/TCU118-W & 0.114285 & 0.1715 \\
\hline 43 & CHICHI/CHY047-N & 0.234162 & 0.1004 & 93 & CHICHI/TCU141-N & 0.151537 & 0.1012 \\
\hline 44 & CHICHI/CHY047-W & 0.161760 & 0.1562 & 94 & CHICHI/TCU141-W & 0.137514 & 0.1317 \\
\hline 45 & CHICHI/CHY054-E & 0.060824 & 0.1979 & 95 & KOBE/KAK000 & 0.251447 & 0.2689 \\
\hline 46 & CHICHI/CHY054-N & 0.076478 & 0.158 & 96 & KOBE/KAK090 & 0.344721 & 0.4245 \\
\hline 47 & CHICHI/CHY076-N & 0.072785 & 0.1338 & 97 & KOBE/NIS000 & 0.509338 & 0.2840 \\
\hline 48 & CHICHI/CHY076-W & 0.072045 & 0.1153 & 98 & KOBE/NIS090 & 0.502749 & 0.2572 \\
\hline 49 & CHICHI/CHY080-N & 0.901702 & 1.8571 & 99 & KOBE/SHI000 & 0.243233 & 0.3321 \\
\hline 50 & CHICHI/CHY080-W & 0.967503 & 1.8974 & 100 & KOBE/SHI090 & 0.211916 & 0.2421 \\
\hline
\end{tabular}

\section{SELECTION OF GROUND MOTION RECORDS}

The selection of appropriate $I M \mathrm{~s}$ is essential in the probabilistic demand analysis and fragility curves development [13]. The two most commonly used $I M$ s, i.e. the spectral acceleration $S_{\mathrm{a}}\left(T_{1}, 5 \%\right)$ at the first fundamental period for $5 \%$ damping or simply $S_{\mathrm{a}}$ and the peak ground acceleration $(P G A)$, are herein considered. Their efficiency, sufficiency, and computability are fully investigated by many research tasks. Based on above mentioned existing research results, the assessment of the $I M \mathrm{~s}$ is not repeated in this study.

This paper is to identify the most fragile component of the typical bridge under the representative larger earthquakes. Hence, seismic records should be appropriately selected considering both a higher seismic intensity and large social influence. The representative events of 1999 Taiwan CHI-CHI (with a Moment 
Magnitude $M_{\mathrm{w}}$ of 7.6) and 1995 Japan KOBE Earthquakes (with $M_{\mathrm{w}}=6.9$ ) are selected, which are both strong earthquake events inducing serious consequences. In addition, the record-to-record uncertainty of ground motions has also been considered using a total of 100 earthquake records from these two events into the seismic analysis. Therefore, reliable qualitative conclusions on the identification of the most fragile component for the subject typical bridge under larger earthquakes can be achieved by the selected representative earthquake events and seismic records. The subset of ground motion records is selected from the NGA-West2 database [8] and briefly listed in Tab. 2.

The suite of records is formed with site-to-source distances $(R)$ more than $10 \mathrm{~km}$ with the aim to reduce the effects of near-fault earthquakes [5]. Due to the limited space, the basic details of the selected ground motion records are shown in Tab. 2 .

\section{PROBABILISTIC SEISMIC DEMAND ANALYSIS 4.1 Selection of Engineering Demand Parameters}

The engineering demand parameters (EDPs) can be sorted to the global and local level groups which represent the different component response related to different performance levels of the structure. It is accepted that the piers and bearings are core elements associated with the performance of the RC continuous bridge. Due to this, the response of these components can be selected as EDPs.

In this study, the relative maximum displacement ductility of piers (denoted as $\mu_{\mathrm{d}}$ ) is selected as the EDP to represent the global demand of the bridge which describes the overall bridge behaviour under seismic loading [14]. Its definition is as follows

$$
\mu_{\mathrm{d}}=\frac{\Delta}{\Delta_{c y 1}}
$$

where $\Delta$ is the maximum horizontal relative displacement between the top node and the bottom node of the pier, $\Delta_{c y 1}$ is the relative displacement when the longitude bars begin to yield.

Meanwhile, the maximum displacement of each bearing $(D)$ in single THA procedure is also selected as the $E D P$ to represent the local demand.

\subsection{Sampling of Earthquake-Structure Samples}

To consider the model uncertainty, four parameters of material are assumed as random variables: $f_{y}$ is the yield strength of reinforcement bars, $E$ is the steel elasticity modulus, $f_{\mathrm{c}}$ is the concrete compressive strength and $f_{\mathrm{cr}}$ is the compressive strength of confined concrete with transverse stirrup reinforcements. The details of distributions of these random variables are shown in Tab. 3 referring to previous research publications [15].

With the aim to reduce the required number of nonlinear THA, the LHS approach is adopted to generate the earthquake-structure samples [9]. In particular, in order to consider the uncertainties of both structural models and ground motions, 100 earthquake-structure samples, including variables of $P G A, S_{\mathrm{a}}, f_{\mathrm{c}}, f_{y}, E, f_{\mathrm{cr}}$, are generated by using LHS approach.

Table 3 Statistical information of material parameters [15]

\begin{tabular}{|c|c|c|c|c|}
\hline $\begin{array}{c}\text { Random } \\
\text { variables }(\mathrm{MPa})\end{array}$ & Distribution & Mean & SD & CV \\
\hline$f_{\mathrm{c}}$ & Lognormal & 26.11 & 4.44 & 0.161 \\
\hline$f_{y}$ & Lognormal & 388.27 & 28.59 & 0.074 \\
\hline$E$ & Lognormal & 204000 & 2040 & 0.08 \\
\hline$f_{\mathrm{cr}}$ & Normal & 27.68 & 4.44 & 0.161 \\
\hline
\end{tabular}

\subsection{Probabilistic Seismic Demand Models}

Assume that each $E D P$ has a lognormal distribution, the conditional mean of the $E D P$ with given $I M$ can be assumed linear in the log-log space, whereas the conditional dispersion is a constant. Thus, the probabilistic demand model (PSDM) can be expressed as follows [16]:

$\ln (\overline{E D P})=a+b \ln (I M)$

in which, $a$ and $b$ are regression parameters, while the logarithmic standard deviation can be obtained as follows

$\beta_{E D P \mid I M}=\sqrt{\frac{\sum_{i=1}^{N}\left(\ln \left(E D P_{i}\right)-\ln (\overline{E D P})\right)^{2}}{N-2}}$

where $N$ is the number of demand data.

Through significance testing of regression analysis, the accuracy of PSDMs can be evaluated. The logarithmic standard deviation $\beta_{E D P I M}$ and the coefficients of determination denoted as $R^{2}$ can be used to evaluate the goodness of fit [17].

Table 4 Parameters of PSDMs and determination coefficients

\begin{tabular}{|c|c|c|c|c|c|}
\hline \multirow{2}{*}{ Directions } & \multirow{2}{*}{ Components } & \multicolumn{4}{|c|}{$P G A$} \\
\hline & & $a$ & $b$ & $\beta_{E D P \mid I M}$ & $R^{2}$ \\
\hline \multirow{4}{*}{ Longitudinal } & Middle pier & 1.26 & 1.36 & 0.57 & 0.44 \\
\hline & Side pier & 0.35 & -2.36 & 0.35 & 0.57 \\
\hline & Fixed bearing & 0.61 & 4.94 & 0.45 & 0.41 \\
\hline & Sliding bearing & 0.93 & 6.06 & 0.54 & 0.44 \\
\hline \multirow{4}{*}{ Transverse } & Middle pier & 1.04 & 1.47 & 0.52 & 0.45 \\
\hline & Side pier & 0.99 & 1.06 & 0.50 & 0.44 \\
\hline & Fixed bearing & 0.54 & 5.18 & 0.40 & 0.41 \\
\hline & Sliding bearing & 0.55 & 4.95 & 0.40 & 0.42 \\
\hline & & \multicolumn{4}{|c|}{$S_{\mathrm{a}}$} \\
\hline \multirow{4}{*}{ Longitudinal } & Middle pier & 1.43 & 0.94 & 0.42 & 0.68 \\
\hline & Side pier & 0.32 & -2.59 & 0.27 & 0.58 \\
\hline & Fixed bearing & 0.72 & 4.77 & 0.33 & 0.69 \\
\hline & Sliding bearing & 1.06 & 5.75 & 0.48 & 0.69 \\
\hline \multirow{4}{*}{ Transverse } & Middle pier & 1.29 & 1.30 & 0.37 & 0.85 \\
\hline & Side pier & 1.24 & 0.92 & 0.36 & 0.85 \\
\hline & Fixed bearing & 0.69 & 5.12 & 0.23 & 0.81 \\
\hline & Sliding bearing & 0.70 & 4.89 & 0.22 & 0.83 \\
\hline
\end{tabular}

The results of PSDMs and the $R^{2}$ are shown in Tab. 4 . As shown in this table, the goodness of fit with the given $S_{\mathrm{a}}$ is better than that of $P G A$. This may be due to that the $S_{\mathrm{a}}$ includes both information of the ground motion and the structure. Moreover, it is found that the goodness of fit in the transverse direction is better than that in the longitudinal direction. Considering the stiffness of $\mathrm{FE}$ model in the longitudinal direction is larger than that in transverse, the dispersion of structural response in the longitudinal direction is more obvious. 


\section{SEISMIC FRAGILITY ANALYSIS}

\subsection{Definition of Damage Limit States}

Under a strong earthquake motion, the pier may experience various extents of seismic damage along with the development of its deformation. Due to this, the damage limit states $(L S s)$ for piers are classified by the values of displacement ductility $\mu_{\mathrm{d}}$. According to Hwang (2000) [18], a total of five damage limit states including no damage, slight damage, moderate damage, extensive damage and complete damage are identified associated with $\mu_{\mathrm{d}}$. With the aim to get the limitations or denoted as damage indices $(D I s)$ for each limit state, the momentcurvature analysis with the RC section is performed [19]. The results of the DIs for piers are shown in Tab. 5 .

Table 5 Damage limit states and the limitations

\begin{tabular}{|c|c|c|c|}
\hline $\begin{array}{c}\text { Damage } \\
\text { limit states }\end{array}$ & $D I$ for piers & $\begin{array}{c}D I \text { for fixed } \\
\text { bearings }(\mathrm{mm})\end{array}$ & $\begin{array}{c}D I \text { for sliding } \\
\text { bearings }(\mathrm{mm})\end{array}$ \\
\hline No damage & $\mu_{\mathrm{d}} \leq 1$ & $D \leq 30$ & $D \leq 100$ \\
\hline Slight & $1<\mu_{\mathrm{d}} \leq 1.07$ & $30<D \leq 50$ & $100<D \leq 150$ \\
\hline Moderate & $1.07<\mu_{\mathrm{d}} \leq 1.31$ & $50<D \leq 100$ & $150<D \leq 200$ \\
\hline Extensive & $1.31<\mu_{\mathrm{d}} \leq 4.31$ & $100<D \leq 255$ & $200<D \leq 500$ \\
\hline Complete & $\mu_{\mathrm{d}}>4.31$ & $D>255$ & $D>500$ \\
\hline
\end{tabular}

The bearing is often another one of the most vulnerable components for RC continuous bridges. Some minor damage to the superstructure occurs while the bearings are severely damaged. The displacement $D$ of bearings is to be used to define the limitation of damage limit states for bearings. According to the presentation in Nielson 2005 [20], the DIs for bearings are also shown in Tab. 5 .

\subsection{Seismic Fragility Curves of Components}

Assume that the $L S$ has a log normal distribution, the fragility denoted as $P_{\mathrm{f}}$ can be defined as follows [21]

$$
P_{\mathrm{f}}=\Phi\left[\frac{-\ln \left(\frac{\overline{L S}}{\overline{E D P}}\right)}{\sqrt{\beta_{L S}^{2}+\beta_{E D P \mid I M}^{2}}}\right]
$$

Where the median of the $L S$ can be selected from Tab. $5, \beta_{L S}$ is the dispersion of the $L S$ with the assumed value of 0.2 in this study [15]. Based on the results of demand analysis and damage analysis, the fragility curves can be developed.

Fig. 3 shows the component fragility curves for piers under longitudinal seismic loading. The shape of the fragility curve for slight damage is similar to the one for the moderate damage. It is shown that the exceedance probability of the middle pier at each intensity level is greater than side piers. Therefore, at the longitudinal loading condition, the most fragile component is the middle pier.

The fragility curves of piers under transverse loading (Fig. 4) show similar results to Fig. 3 except the exceeding probability of the side piers. It can be seen that the curve shape of the side pier is similar to those of the middle pier. That is because the movement of the sliding bearing in the transverse direction is limited, which can be calculated as fixed bearing under transverse loading.

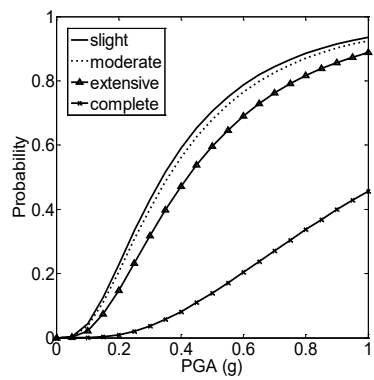

(a) Middle pier $\sim P G A$

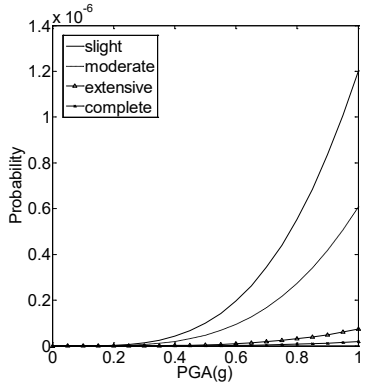

(c) Side pier $\sim P G A$

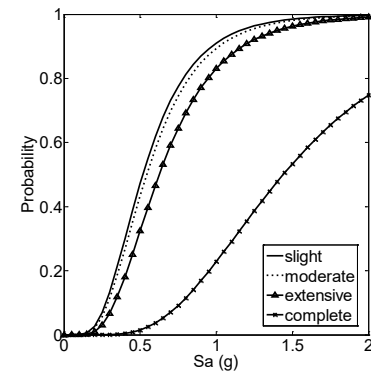

(b) Middle pier $\sim S_{a}$

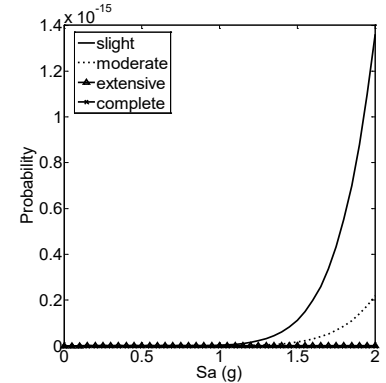

(d) Side pier $\sim S_{a}$
Figure 3 Component fragility curves for piers with selected IMs at longitudinal loading condition

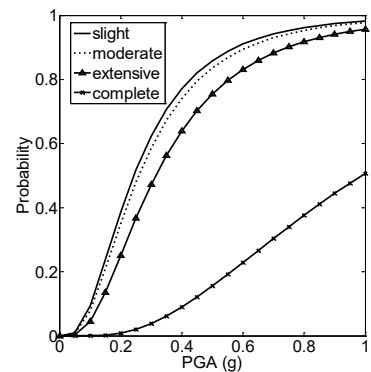

(a) Middle pier $\sim P G A$

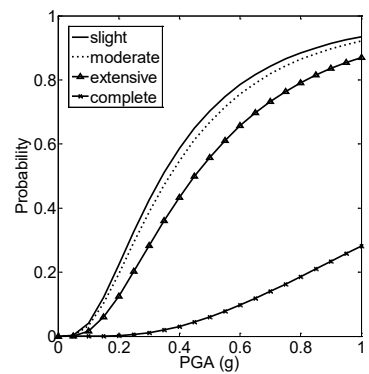

(c) Side pier $\sim P G A$

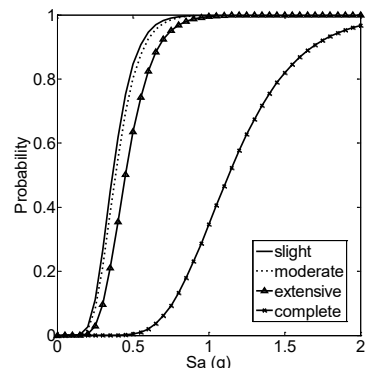

(b) Middle pier $\sim S_{\text {a }}$

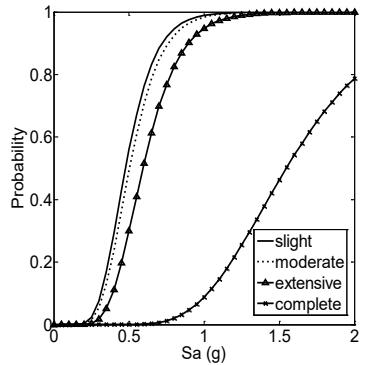

(d) Side pier $\sim S_{a}$
Figure 4 Component fragility curves for piers with selected IMs at transverse loading condition

Fig. 5 shows the component fragility curves for bearings under the longitudinal loading of earthquakes. The exceedance probabilities of slight damage and moderate damage for the fixed bearings are greater than the sliding bearings. However, with damage development from extensive state to complete state, the exceedance probability of damages at extensive and complete states for the sliding bearing is greater than that for the fixed bearing. The reason is that the stiffness of sliding bearings is nonlinear as the increase of the displacement. 


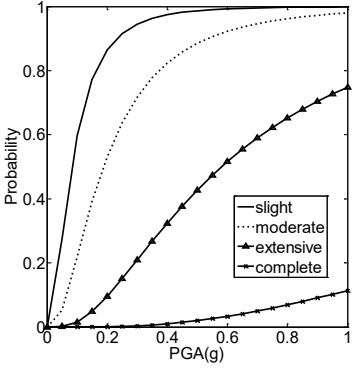

(a) Fixed bearing $\sim P G A$

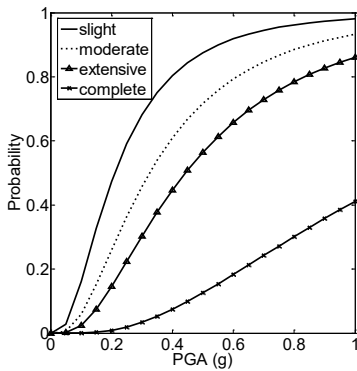

(c) Sliding bearing $\sim P G A$

Figure 5 Component fragility curves for bearings with selected IMs longitudinal loading condition

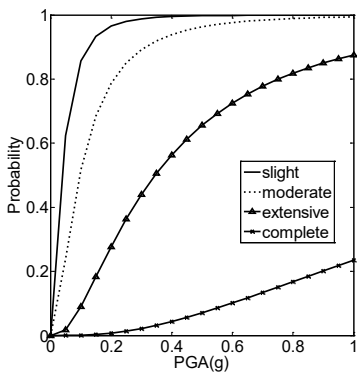

(a) Fixed bearing $\sim P G A$

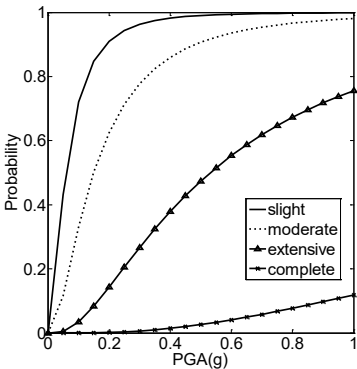

(c) Sliding bearing $\sim P G A$

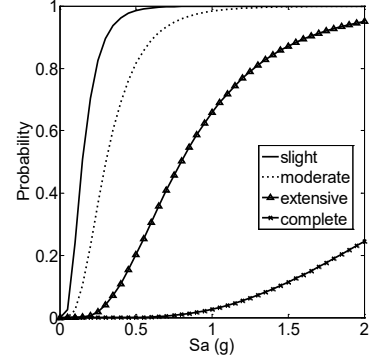

(b) Fixed bearing $\sim S_{a}$

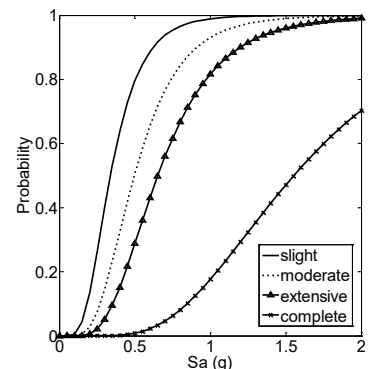

(d) Sliding bearing $\sim S_{a}$

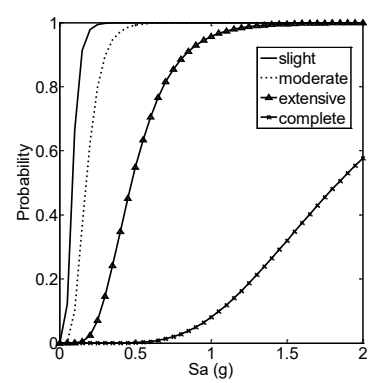

(b) Fixed bearing $\sim S_{\text {a }}$

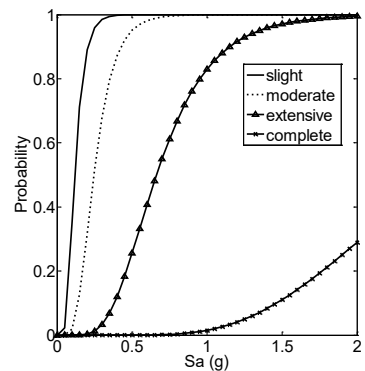

(d) Sliding bearing $\sim S_{a}$

Figure 6 Component fragility curves for bearings with selected IMs at transverse loading condition

Moreover, the component fragility curves for bearings at the condition of transverse loading are shown in Fig. 6. As shown in this figure, the exceedance probability for fixed bearings is greater than that for the sliding bearings under each damage limit state in the entire range of selected seismic intensity levels. The difference result between longitudinal and transverse directions may be attributed to the stiffness difference of bearings in these two directions.

Based on the component fragility results, it is found that the bearings are more fragile than piers. The fixed bearing is the most fragile component at the condition of transverse seismic loading. However, at the condition of the longitudinal seismic loading the fixed bearing is the most fragile component for relative lower damage states, while the sliding bearing is the most fragile component for relative higher damage states. Stiffness of the component is the major reason causing different damage development trends during the seismic loading process. The larger stiffness will induce larger response under the same loading condition and the higher failure probability.

\subsection{Seismic Fragility Curves of Systems}

By integrating fragility curves of bridge components, the fragilities of bridge systems can be obtained. Assume that the components are mutually independent, and then the bridge system failure probability is expressed as follows

$$
P_{\mathrm{fs}}=1-\prod_{i=1}^{n}\left[1-P_{\mathrm{f} i}\right]
$$

in which, $P_{\mathrm{fs}}$ is the system failure probability, $P_{\mathrm{f} i}$ is the failure probability of the $i^{\text {th }}$ component.

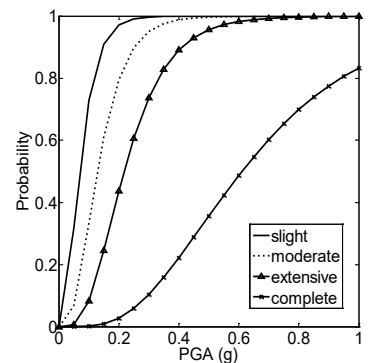

(a) Longitudinal $\sim P G A$

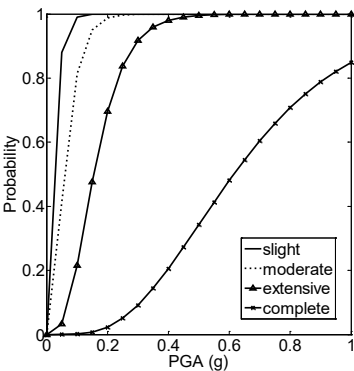

(c) Transverse $\sim P G A$

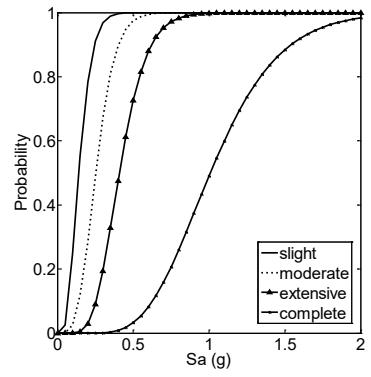

(b) Longitudinal $\sim S_{a}$

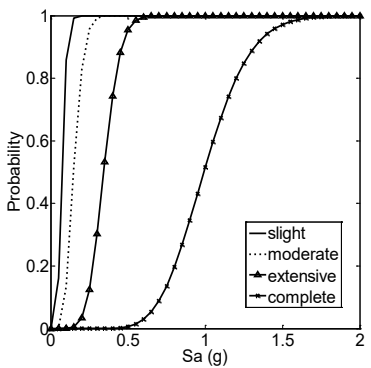

(d) Transverse $\sim S_{a}$
Figure 7 System fragility curves with selected IMs at conditions of the transverse and longitudinal loading

By using Eq. (7), the system fragility curves are obtained and presented in Fig. 7. It should be noted that system fragility under the longitudinal loading is always smaller than that under the transverse loading condition. In addition, the system failure probability associated with $S_{\text {a }}$ is greater than that associated with $P G A$. Considering the safety of the results of structural performance assessment, the $S_{a}$ may be more commended to be used.

\section{CONCLUSION}

A representative $\mathrm{RC}$ continuous girder bridge designed according to China bridge design code is investigated as the study case. The seismic fragility analysis of the bridge is carried out and the most fragile component is identified. Based on the results, several conclusions are drawn:

The middle pier is more fragile than the side pier because of the arrangement of the fixed bearings at the middle pier. However, the fixed bearing is not always the most fragile component. It is found that the sliding bearing is more fragile than fixed bearings for relative higher 
damage states at the transverse seismic loading condition. To accurately estimate the seismic loss and repair cost after disasters, it is necessary to analyse the specific bridge model rather than make a decision based on experiences.

Due to the fact that the system fragility of the typical bridge in the transverse direction is greater than that in longitudinal, the conclusion that the transverse bridge dynamic behaviour is actually more critical than the longitudinal has been validated for the RC continuous girder bridges. In addition, $S_{\mathrm{a}}$ is recommended for the fragility assessment based on this case study.

\section{Acknowledgements}

The financial supports received from the National Science Foundation of China (Grant Nos. 51678209, 51378162), the Ministry of Science and Technology of China (Grant No. 2013BAJ08B01), and the Open Research Fund of State Key Laboratory for Disaster Reduction in Civil Engineering (Grant No. SLDRCE12-MB-04) are gratefully appreciated.

\section{REFERENCES}

[1] Nielson, B. G., \& DesRoches, R. (2007). Seismic fragility methodology for highway bridges using a component level approach. Earthquake Engineering \& Structural Dynamics, 36(6), 823-839. https://doi.org/10.1002/eqe.655

[2] Karim, K. R., \& Yamazaki, F. (2001). Effect of earthquake ground motions on fragility curves of highway bridge piers based on numerical simulation. Earthquake engineering \& structural dynamics, 30(12), 1839-1856. https://doi.org/10.1002/eqe.97

[3] Günay, S., \& Mosalam, K. M. (2013). PEER performancebased earthquake engineering methodology, revisited. Journal of Earthquake Engineering, 17(6), 829-858. https://doi.org/10.1080/13632469.2013.787377

[4] Lu, D., Yu, X., Jia, M., \& Wang, G. (2014). Seismic risk assessment for a reinforced concrete frame designed according to Chinese codes. Structure and Infrastructure Engineering, 10(10), 1295-1310. https://doi.org/10.1080/15732479.2013.791326

[5] Baker, J. W., Lin, T., Shahi, S. K., \& Jayaram, N. (2011). New ground motion selection procedures and selected motions for the PEER transportation research program. Peer Report 2011, 3.

[6] Cornell, C. A., Jalayer, F., Hamburger, R. O., \& Foutch, D. A. (2002). Probabilistic basis for 2000 SAC federal emergency management agency steel moment frame guidelines. Journal of structural engineering, 128(4), 526533. https://doi.org/10.1061/(ASCE)0733-9445(2002)128:4(526)

[7] Jalayer, F., Ebrahimian, H., Miano, A., Manfredi, G., \& Sezen, H. (2017). Analytical fragility assessment using unscaled ground motion records. Earthquake Engineering \& Structural Dynamics, 46(15), 2639-2663. https://doi.org/10.1002/eqe.2922

[8] Ancheta, T. D., Darragh, R. B., Stewart, J. P., Seyhan, E., Silva, W. J., Chiou, B. S.-J., et al. (2014). NGA-West2 database. Earthquake Spectra, 30(3), 989-1005. https://doi.org/10.1193/070913EQS197M

[9] Iman, R. L. (2008). Latin hypercube sampling. Encyclopedia of quantitative risk analysis and assessment. https://doi.org/10.1002/9780470061596.risk0299

[10] JTG. (2004). JTG D62-2004 Code for design of highway reinforced concrete and prestressed concrete bridges. China, M. o. T. o. t. P. s. R. o. Beijing, China.
[11] JTG. (2008). JTG/T B02-01-2008 Guideline for seismic design of highway bridges. China, M. o. T. o. t. P. s. R. o. Beijing, China.

[12] Mazzoni, S., McKenna, F., \& Fenves, G. L. (2005). OpenSees command language manual. Pacific Earthquake Engineering Research (PEER) Center, 264.

[13] Padgett, J. E., Nielson, B. G., \& DesRoches, R. (2008). Selection of optimal intensity measures in probabilistic seismic demand models of highway bridge portfolios. Earthquake Engineering \& Structural Dynamics, 37(5), 711725. https://doi.org/10.1002/eqe.782

[14] Tondini, N. \& Stojadinovic, B. (2012). Probabilistic seismic demand model for curved reinforced concrete bridges. Bulletin of Earthquake Engineering, 10(5), 1455-1479. https://doi.org/10.1007/s10518-012-9362-y

[15] Padgett, J. E. \& DesRoches, R. (2007). Sensitivity of seismic response and fragility to parameter uncertainty. Journal of Structural Engineering, 133(12), 1710-1718. https://doi.org/10.1061/(ASCE)0733-9445(2007)133:12(1710)

[16] Liu, Y., Lu, D. G., \& Paolacci, F. (2015). Multivariate Probabilistic Seismic Demand Analysis of Steel-concrete Composite Bridges under Near-fault Pulse-like Ground Motions. Multispan Large Beidges, Porto. https://doi.org/10.1201/b18567-133

[17] Liu, Y., Paolacci, F., \& Lu, D. G. (2017). Seismic fragility of a typical bridge using extrapolated experimental damage limit states. Earthquakes \& Structures, 13(6), 599-611. https://doi.org/10.12989/eas.2017.13.6.599

[18] Hwang, H., Jernigan, J. B., \& Lin, Y. W. (2000). Evaluation of seismic damage to Memphis bridges and highway systems. Journal of Bridge Engineering, 5(4), 322-330. https://doi.org/10.1061/(ASCE)1084-0702(2000)5:4(322)

[19] CALTRANS. (2001). Seismic Design Criteria, Version 1.2. Transportation, C. D. o. Sacramento, California, USA.

[20] Nielson, B. G. (2005). Analytical fragility curves for highway bridges in moderate seismic zones (Doctoral dissertation, Georgia Institute of Technology).

[21] Liu, Y., Lu, D. G., \& Paolacci, F. (2016). Probabilistic seismic resilience analysis for bridges shocked by near-fault pulse-like ground motions. Maintenance, Monitoring, Safety, Risk and Resilience of Bridges and Bridge Networks, 42(10), 230.

\section{Contact information}

Yang LIU, PhD, Assistant Professor

(Corresponding author)

Key Laboratory of Deep Underground Science and Engineering

(Ministry of Education), Sichuan University, Chengdu, China

E-mail: yangliuscu@scu.edu.cn

Da-Gang LU, PhD, Full Professor

Harbin Institute of Technology, Harbin, China

E-mail: ludagang@hit.edu.cn

Ming-Gang HUANG, M.D. Candidate

Harbin Institute of Technology, Harbin, China 